\title{
High-severity wildfire limits available floral pollen quality and bumble bee nutrition compared to mixed-severity burns
}

\section{Authors: Michael P. Simanonok \& Laura A. Burkle}

This is a postprint of an article that originally appeared in Oecologia on Decmber 16, 2019. The final version can be found at doi: 10.1007/s00442-019-04577-9

Simanonok, Michael P., and Laura A. Burkle. "High-Severity Wildfire Limits Available Floral Pollen Quality and Bumble Bee Nutrition Compared to Mixed-Severity Burns." Oecologia 192, no. 2 (December 16, 2019): 489-499. doi:10.1007/s00442-019-04577-9. 


\title{
High-severity wildfire limits available floral pollen quality and bumble bee nutrition compared to mixed-severity burns
}

\author{
Michael P. Simanonok ${ }^{1,2}$ - Laura A. Burkle ${ }^{1}$ \\ Michael P. Simanonok \\ mikesimanonok@gmail.com \\ 'Department of Ecology, Montana State University, Bozeman, MT, USA \\ 2U.S. Geological Survey, Northern Prairie Wildlife Research Center, 8711 37th St SE, Jamestown, ND 58401-7317, US
}

\begin{abstract}
High-severity wildfires, which can homogenize floral communities, are becoming more common relative to historic mixed-severity fire regimes in the Northern Rockies of the U.S. High-severity wildfire could negatively affect bumble bees, which are typically diet generalists, if floral species of inadequate pollen quality dominate the landscape post-burn. High-severity wildfires often require more time to return to pre-burn vegetation composition, and thus, effects of highseverity burns may persist past initial impacts. We investigated how wildfire severity (mixed- vs. high-severity) and time-since-burn affected available floral pollen quality, corbicular pollen quality, and bumble bee nutrition using percent nitrogen as a proxy for pol-len quality and bumble bee nutrition. We found that community-weighted mean floral pollen nitrogen, corbicular pollen nitrogen, and bumble bee nitrogen were greater on average by $0.82 \% \mathrm{~N}, 0.60 \% \mathrm{~N}$, and $1.16 \% \mathrm{~N}$, respectively, in mixed-severity burns. This pattern of enhanced floral pollen nitrogen in mixed-severity burns was likely driven by the floral community, as community-weighted mean floral pollen percent nitrogen explained $87.4 \%$ of deviance in floral community composition. Only bee percent nitrogen varied with time-since-burn, increasing by $0.33 \% \mathrm{~N}$ per year. If these patterns persist across systems, our findings suggest that although wildfire is an essential ecosystem process, there are negative early successional impacts of high-severity wildfires on bumble bees and potentially on other pollendependent organisms via reductions in available pollen quality and nutrition. This work examines a previously unexplored pathway for how disturbances can influence native b ee success via altering the nutritional landscape of pollen.
\end{abstract}

\section{Introduction}

Pollen provides bumble bees (Bombus spp.) with nearly all proteins, lipids, and other non-carbohydrate nutrients received during their lifetime, with pollen primarily provisioned to individuals when they are larvae (Goulson 2003). Foraging bumble bees frequently show preference for higher quality pollen, which is typically quantified as protein (Hanley et al. 2008), protein:lipid ratio (Vaudo et al. 2016), or amino acids (Hanley et al. 2008), and which they discern via a combination of visual, tactile, and olfactory cues (Mapalad et al. 2008; Kitaoka and Nieh 2009; Ruedenauer et al. 2015; Vaudo et al. 2016). Higher pollen nitrogen, a common proxy for protein content of pollen (Roulston et al. 2000), can increase individual larval weight and body size (Tasei and Aupinel 2008; Vanderplanck et al. 2014). Importantly, pollen quantity does not confer the same benefits (Filipiak 2018); pollen quantity is typically associated with the number of workers a colony produces (e.g., Kämper et al. 2016; Rotheray et al. 2017), while pollen quality is more directly related to individual bee health and survival (e.g., Vanderplanck et al. 2014). Low-quality diets are often insufficient in nutrient content, amino acids, or stoichiometric balance, and thus, higher quantity does not typically compensate for lower quality pollen (Filipiak 2018). However, some studies have found that if essential nutrients are provided, then costs 
of low-quality pollen can be at least partially offset (Kämper et al. 2016).

The availability of floral species whose pollens differ in quality - the available "nutritional landscape" may influence patterns of foraging and bumble bee nutrition in ways that cannot be explored experimentally (Woodard and Jha 2017). Corbicular pollen loads collected by foraging workers typically include a mixture of plant species (Ruedenauer et al. 2016; Kriesell et al. 2017), and the composition of pollen species collected is often a reflection of the landscape of floral species and their pollen nutrients (Saifuddin and Jha 2014; Kriesell et al. 2017). As the composition of floral communities and thus the overall quality of the suite of available pollen varies across space and time, often due to anthropogenic factors, patterns of bumble bee foraging, and nutrition might vary as well (Woodard and Jha 2017). Studying the nutrition available in floral resources at the community level and how it may vary across habitats is highlighted as the next essential step in linking the nutritional landscape to bee nutrition (Vaudo et al. 2018). Given ongoing pollinator declines globally, understanding how bees forage across their environment and how that nutritional landscape varies in the face of anthropogenic effects is an important frontier in supporting bee health (Corby-Harris et al. 2019).

Disturbances, like wildfire, influence the diversity and composition of floral resources (e.g., Hessburg et al. 1999; Abella and Fornwalt 2015; Burkle et al. 2015) which thereby could affect bumble bee foraging and nutrition. Across ecosystems, fire can dramatically alter nutrient availability as well as the quality and quantity of forage (e.g., Wan et al. 2001), particularly for organisms which may forage across a landscape scale over the course of a growing season (Milchunas and Lauenroth 1993). However, despite a long history of research on nutritional limitation in invertebrates (e.g., Elser et al. 2000), there has been little work addressing how bee forage and nutrition interact (Filipiak 2018) or how such relationships may be influenced by fire. Nectar and pollen have been studied in the initial years immediately following burning, finding that nectar and pollen energy $(\mathrm{kcal} / \mathrm{g})$ were highly variable with time-since-burn and that pollen energy generally declines with increasing time-since-burn (Potts et al. 2003). Energy content, while important, provides little-to-no insight to the chemical or nutritional content of the nectar or pollen. Floral pollen quality after fire is more likely to be determined by what floral species are present as opposed to among-site variation in soil nutrients. Pollen quality, specifically protein, is strongly conserved within phylogenies (Roulston et al. 2000), since pollen functions to produce gametes and is thus constrained by sexual selection. However, fire has been observed to affect pollen tube growth rate of at least one species via altered soil nutrients (e.g., phosphorus and potassium, Travers 1999), suggesting that pollen quality and the nutritional landscape of pollen available to bees in post-fire landscapes may be influenced independently of floral community composition. In either case, there is currently a gap in our knowledge in how bees interact with the nutritional landscape of pollen resources available to them, as well as how that nutritional landscape may be affected by disturbances like wildfire.

With changing wildfire regimes, including increasing fire severities, areas historically dominated by patchy, mixed-severity fires are becoming typified by large-scale, homogenizing high-severity burns (Hessburg et al. 2005; Bowman et al. 2009). The effects of high-severity fires on floral community composition can persist for several years longer than the effects of mixed-severity fires, where effects on floral communities are most evident immediately following wildfire and communities rapidly approach preburn floral composition (Abella and Fornwalt 2015). Highseverity burns may be detrimental to bumble bee nutrition if flowering species with low-quality pollen dominate after high-severity burns. For example, high-severity burns, when compared to more pyrodiverse burns, can have lower floral species richness locally as well as reduced beta-diversity across the landscape (Ponisio et al. 2016; Lazarina et al. 2019; LaManna et al. in review). However, high-severity burns have also been noted to have high bee abundance, particularly for bumble bee species (Galbraith et al. 2019, Burkle et al. 2019). Mixed-severity burns are comprised of a patchwork of low-to-high-severity burns, and can generate a greater diversity of flowering species and habitats across the landscape (Hessburg et al. 2005; Ponisio et al. 2016), providing foraging bumble bees with a greater diversity of pollen and lowering the odds of low-quality forage species dominating post-burn areas compared to high-severity burns. In post-burn landscapes, understanding how floral resources like the suites of pollen available after wildfire influence bumble bee foraging and nutrition could thus help with conserving and managing pollinators (Woodard and Jha 2017).

We sought to investigate how shifts in floral resources associated with wildfire severity and time-since-burn influenced the quality of available floral pollen as well as bumble bee nutrition. Comparing high- and mixed-severity burns across three wildfires ranging from 1 to 7 years post-burn in southwest Montana USA, we investigated differences in (1) the quality of floral pollen in the floral community, using percent nitrogen as our proxy for quality, (2) the percent nitrogen of pollen in corbicular loads of bumble bees, and (3) bumble bee body percent nitrogen.

\section{Methods}

\section{Study system}

To study the ecological effects of wildfire on bumble bee nutrition and foraging, we used a chronosequence (Hutto and 
Belote 2013) of three wildfires from the Absaroka Mountains, Montana USA (Fig. 1, Table 1). Wildfires occurred within $30 \mathrm{~km}$ of each other and are similar in other environmental characteristics (i.e., elevation, aspect, and slope; Table 1) except for time-since-burn. Our sampling of this time-since-burn chronosequence covered 1, 2, and 7 years post-burn. To compare bee foraging and nutrition between mixed- and high-severity fire, we selected two 15 ha sampling blocks of homogenous high-severity burn and two of heterogeneous mixed-severity burn within each wildfire perimeter. Within each block, we established nine sampling plots: a mixed-severity block was comprised of three lowseverity plots, three moderate-severity plots, and three highseverity plots, while a high-severity block contained nine high-severity plots. Mixed-severity blocks were designed with this range of local severities and habitat variability to represent a heterogeneous landscape treatment to compare against large areas of high-severity. Given that plots within a block were on average $139.4 \mathrm{~m}$ from the next nearest plot, we expected that bumble bee workers were able

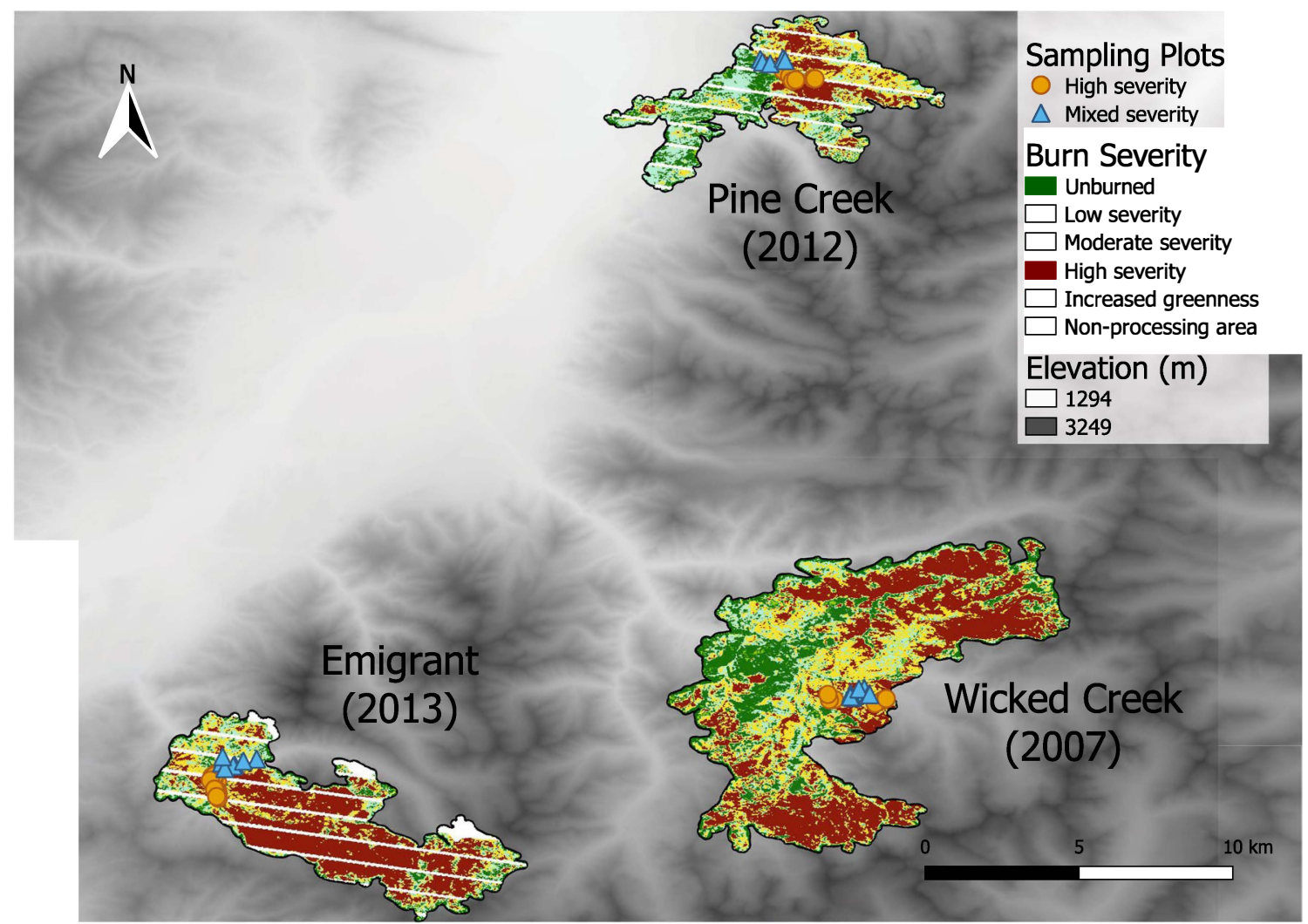

Fig. 1 Map of the study area with burn perimeters, burn severity, and sampling plots. The "non-processing area" class present for the Emigrant and Pine Creek fires is scanning gaps for which no burn severity data are available. See Table 1 for further detail

Table 1 Name, location, ignition date, and average characteristics of sampling plots within wildfires, as well as the number of plots and bees per burn severity from each wildfire

$\begin{array}{ll}\text { Fire name } & \text { Emigrant } \\ \text { Location } & 45.23^{\circ},-110.73^{\circ} \\ \text { Ignition date } & \text { August } 16,2013 \\ \text { Area (acres) } & 11,834 \\ \text { Elevation (m) } & 1914.35 \\ \text { Aspect }\left(^{\circ}\right) & 102.44 \\ \text { Slope }\left(^{\circ}\right) & 21.03 \\ \text { \# Plots (high, mixed) } & 13,7 \\ \text { \# Bees (high, mixed) } & 19,15\end{array}$

\# Bees (high, mixed)
Pine Creek

$45.52^{\circ},-110.50^{\circ}$

August 29, 2012

8572

1952.24

141.32

22.35

8,5

11,7
Wicked Creek

$45.26^{\circ},-110.47^{\circ}$

August 7, 2007

28,674

2119.06

94.82

17.64

6,8

8,12

Location's latitude and longitude is an approximate centroid of sampling plots located within each wildfire perimeter. Elevation, aspect, and slope are mean values for sampling plots within each wildfire 
to forage among plots within a block (e.g., mean foraging range $-275 \mathrm{~m}$, Osborne et al. 20010. Wildfire severity data were acquired from the Monitoring 'Irends in Burn Sever ity pruject (Eidenshink et al. 2007). Within these design consirants, plots were randomly placed using Generalized Random 'lesselation Stratified Spatial Sampling, which accounts for the spatial distribution of plots to minimize clusterning (Kincald and Olsen 20110 Within each of two 15 ha blocks of unburned forest, nine plots were selected and sampled for this study. However, anong the nine bumble bee wurkers collected in these unburned plots, only one had intact curbicular pollen, therefore, the unburned plots were excluded frum analyses. Fur comparison, 720 tutal bumble bee wurkers were collected across these burned plots in 2014 (Simanonok 2018).

\section{Field sampling}

Each plot was a $25 \mathrm{~m}$ diameter curcle and contained a $25 \mathrm{~m}$ x $2 \mathrm{~m}$ baud transect ceutered on the plot. In each plot, we halud-netted bumble bees that we observed visiting ope.⿲丿 flowers for 20 minn al least once per week over the flowering seasun, tutaling 133 obser vation hours across all plots (early June late August) in 2014. We censused floral abundance of each plant species within the band transect concuneut with bumble bee hand nettny. All bees collected and included in allalyses were workers, queens were nut destructively sainpled and males were excluded from analyses. A subsannple ( $N-72$ individuals, cia. $10 \%$ of total capture) of collected bumble bees that had intact corbicular pollen were ralldomly selected for chemulcal analyses. Subsannple number was dictated by budgecan y cunstraints, while the largen fieldcollected sample was collected as part of a larger project (Simlanonok 2018). Alıalyzed bees were piinarily Bumbus bifarius $(N-53)$, blut also micluded $B$. centralis (NQ-4), $B$. hurttl ' $(N-1), B$. muxtus ' $(N-8), B$. occidentalis $(N-2)$, and $B$. rufocinctus $(N-4)$. Bees were ideutified to species following Kuch et al. (2012). Only floral data of plots from which this subsaunple of bees were collected were included in alıalyses (i.e., 57 or 108 cotal plots, lable 1). These bunnble bees were used to assess body percent nitrugen, and their evibiculan pollen salniples were used to meiasure the percent antrugen of thenr corbicula poillen luadso See Online Resuuce I fon law data fon undividual bee budy percent ultrugen alld evibicuiar pollen nitrugen.

lo assess pollen percent mutrogen of floral species and thus :he communty- welghted mean percent aitrogen of floral pollen, minters were cullecoed from eornmon floral specules klıuwin to be visilted by bumble bees in this system in 2064 and 20ф). Pollen sanmies of eatin floral species wene pouled ticiuss 111 piots sven the seidson o juvide sulficiently lange poilen samples for maliysis. See Online Resuurce 2 for raw daca for Horal species poillen percent nitrugen.

\section{Lab methods}

We quantified percent nitrogen for all pollen and bee samples. Tu do this, we renoved corbicular pollen from each bee, then lyophilized whole bee specimens and pollen samples for $8 \mathrm{~h}$, and weighed them afterward. Bumble bees were then homogenized using a mortar and pestle, from which a $5 \mathrm{mg}$ subsample was taken. Anthers were suspended in ethanol, sonicated for $1 \mathrm{~min}$ at $40 \mathrm{kHz}$, and then centrifuged for $1 \mathrm{~min}$ at $2400 \mathrm{rpm}$, after which the isolated pollen was removed with forceps. All samples (i.e., anther pollen, corbicular pollen, and bee) were combusted in a Costech ECS 4010 Nitrogen/Protein Analyzer which uses gias chromatography to determine total nitrugen cuntent. Whereas recent research performed, since the initiation of this project has identified more nuanced metrics of pollen quality relevant for bee nutrition, e.g., the ratio of proteins to lipids (Vaudo et al. 2016), we report percent nitrogen, which, albeit a more coarse assessment of "quality," is relatively simple and inexpensive to measure and can be used to compare quality or broad stoichiometric relationships across trophic levels (i.e., pollen and pollen consumers).

\section{Statistical analyses}

\section{Floral abundance, richness, and composition}

We tested for difterences in floral abundance and richness between burn severities, across time-since-burn, and the interactive effect of burn severity and time-since-burn using linear regression. lo begin to understand the composition of floral pollen available tt each samupling pl st, we tested for differences in the floral community between burn severities and across time-since burn with a permutational multivariate malysis of variance (PERMANOVA). We further assessed which floral species contributed to community dissimilarity between burn severities and tcross time-since-burn with the simper function in R package vegall (Oksanen et al. 2018).

\section{Quality of florial pollen}

To compare the quality of tvailable floral pollen between burn severities and tcross time-since-burn, we calculated the community-weighted mean (CWM) percent nitrogen of floral pollen tvailable in each plot as the percent nitrogen of anther-sollected pollen of all floral species in bloom during the week in which that bee species was collected from that plot. weighted oy floral sbundance:

$\sum_{i, 1, x_{i}} n_{i} \times x_{i}$

For zaden sampling piot, $n$ is the percent nitrogen for spezies $i, x_{i}$ is floral toundance of species $i . x_{+}$is the total floral 
abundance of all species at that plot, and $i \ldots j$ represents the first (i) through last $(j)$ species present at the plot. To test for differences in floral pollen quality among plots, we used a linear mixed-effects model comparing community-weighted mean floral pollen percent nitrogen between mixed- and high-severity, across time-since-burn, and their interaction, including plot as a random effect. We used non-metric multidimensional scaling (NMDS) ordination to visualize any differences in the floral community between burn severities, and we overlaid the distribution of CWM floral pollen percent nitrogen across the floral community using a surface generalized additive model with the ordisurf function in $\mathrm{R}$ package vegan (Oksanen et al. 2018).

\section{Quality of corbicular pollen}

To test whether corbicular pollen quality (i.e., percent nitrogen) varied across burn severities and time-since-burn as well as to investigate whether corbicular pollen quality was affected by available pollen quality, we used a linear mixedeffects model of corbicular pollen percent nitrogen compared against burn severity, time-since-burn, their interaction, CWM available pollen percent nitrogen of the plot from which the bee was captured during the same week of sampling, and pollen percent nitrogen of the species of flower from which the bee was netted. Sampling plot was included as a random effect. Additionally, we assessed whether corbicular pollen was different across bee species with an analysis of variance (ANOVA). Six observations were removed as we lacked pollen protein data for some visited plant species.

\section{Bumble bee nutrition}

First, we tested for differences in body percent nitrogen among bumble bee species with an ANOVA. Then, to test how bee nutrition varied across burn severities and timesince-burn, we used a linear mixed-effects model comparing bee percent nitrogen against burn severities, time-sinceburn, and their interaction. Plot identity was included as a random effect. All analyses were performed in $\mathrm{R}$ version 3.5.1 with the $1 m e 4$, lmerTest, labdsv, and vegan packages (Bates et al. 2015; Roberts 2016; Kuznetsova et al. 2017; Oksanen et al. 2018; R core team 2018).

\section{Results}

\section{Floral abundance, richness, and composition}

Floral abundance was similar between mixed- and highseverity plots $(t=1.28, p=0.20$, Fig. $2 \mathrm{a})$, did not vary across time-since-burn $(t=0.34, P=0.73)$, and there was no interactive effect of burn severity with time-since-burn on floral abundance $(t=-0.56, P=0.57)$. However, mean floral richness was ca. 2 species greater in mixed-severity plots $(t=3.53, P<0.01$, Fig. $2 \mathrm{~b})$, although floral richness did not vary with time-since-burn $(t=-0.74, P=0.46)$ or interactively with burn severity and time-since-burn $(t=-0.99, P=0.32)$. Floral community composition was significantly different between burn severities and across time-since-burn (Fig. 3, Table 2). For burn severity, four species accounted for $76 \%$ of the variability: Symphoricarpos albus, Chamaenerion angustifolium, Lupinus sericeus, and Spiraea betulifolia (see Online Resource 3 for full output). S. albus was highly abundant in both mixed- and high-severity, but more abundant in mixed-severity overall. C. angustifolium and S. betulifolia were more common in high-severity plots, while L. sericeus was common in mixed-severity plots (see Online Resource 3 ). For timesince-burn, S. albus accounted for $40 \%$ of community differences between years 1 and 2, C. angustifolium for $27 \%$ between burn years 1 and 7, and C. angustifolium again was the highest differentiator between years 2 and 7 with 28\% (see Online Resource 3).
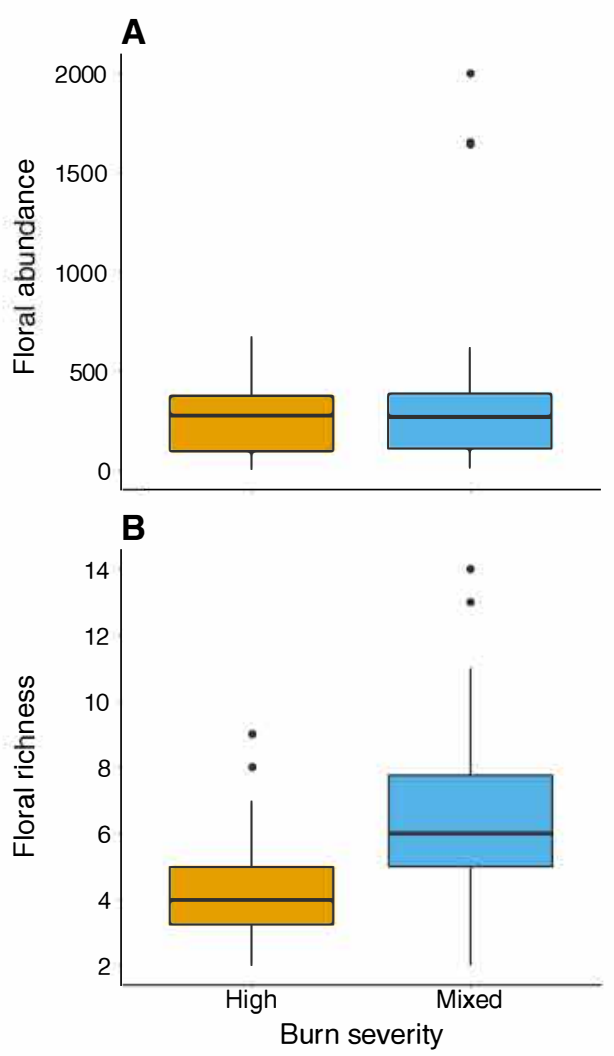

Fig. 2 a Floral abundance (no. flowers) by burn severity, and $\mathbf{b}$ floral richness (no. species) by burn severity 


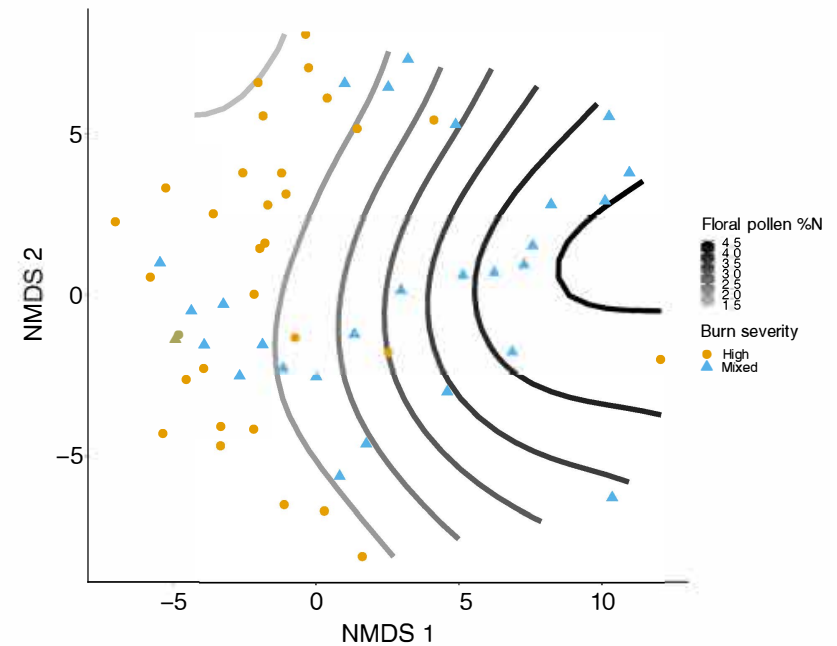

Fig. 3 Non-metric multidimensional scaling ordination with mixedseverity plots as blue triangles and high-severity plots as orange circles. Surface contours are shaded from black to gray based on the community-weighted mean floral percent nitrogen of the floral community

\section{Quality of available floral pollen}

Anther-collected pollen varied from 1.07 to $5.24 \% \mathrm{~N}$ for the 32 floral species collected. CWM floral pollen percent nitrogen was $0.82 \% \mathrm{~N}$ greater in mixed- vs. high-severity plots ( $t=2.29, N=72, P=0.028$, Fig. 4 ), but there was no significant change with time-since-burn $(t=1.25, N=72, P=0.22)$ and no interactive effect between burn severity and timesince-burn ( $t=0.45, N=72, \mathrm{P}=0.65)$. CWM floral pollen percent nitrogen explained $87.4 \%$ of deviance in the floral community NMDS $\left(R^{2}=0.86, \mathrm{REML}=42.91\right.$, scale estimate $=0.16$, Fig. 3 ) with high-severity plots generally having lower floral pollen protein compared to mixed-severity plots (Fig. 3).

\section{Quality of corbicular pollen}

Corbicular pollen samples ranged from 2.58 to $7.44 \% \mathrm{~N}$. Corbicular pollen nitrogen did not vary among bee species $\left(F_{5,66}=1.33, P=0.26\right)$. Corbicular pollen percent nitrogen was marginally greater by $0.60 \% \mathrm{~N}$ in mixed-severity

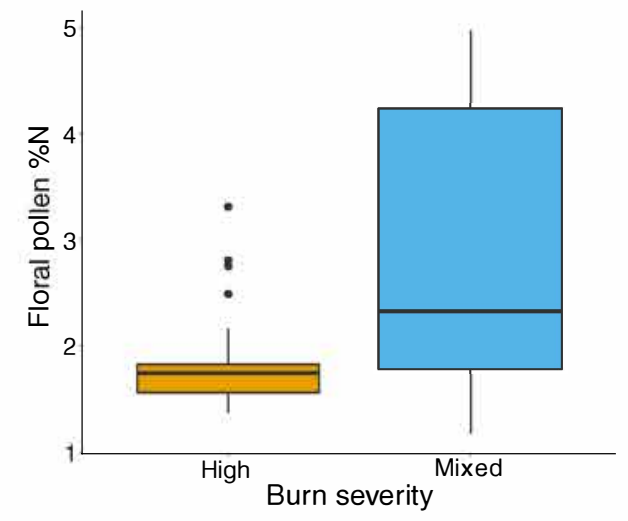

Fig. 4 Community-weighted mean floral pollen percent nitrogen by burn severity

plots than in high-severity plots $(t=1.722, N=66, P=0.10$, Fig. 5a), with no significant change across time-since-burn ( $t=0.85, N=66, P=0.40)$, and no interaction between burn severity and time-since-burn $(t=-1.08, N=66, P=0.29)$. Corbicular pollen percent nitrogen increased by $0.51 \% \mathrm{~N}$ with each $1 \%$ increase in CWM floral pollen percent nitrogen $(t=3.05, N=66, P<0.01$, Fig. 5b). However, corbicular pollen percent nitrogen was unrelated to the pollen percent nitrogen of the plant from which the bee was collected $(t=1.21, N=66, P=0.23)$.

\section{Bumble bee nutrition}

Bumble bee percent nitrogen ranged from 6.97 to $12.52 \% \mathrm{~N}$ and did not vary among bumble bee species $\left(F_{5,66}=0.49\right.$, $P=0.78)$. Bumble bee percent nitrogen was $1.16 \% \mathrm{~N}$ higher in mixed- than in high-severity plots $(t=2.36, N=72$, $P=0.02$, Fig. 6a) and also increased with time-since-burn by $0.33 \% \mathrm{~N}$ per year $(t=3.58, N=72, P<0.01$, Fig. $6 \mathrm{~b})$. There was minimal evidence of an interactive effect between burn severity and time-since-burn $(t=-1.62, N=72, P=0.11)$.
Table 2 PERMANOVA results of floral community composition across burn severity, time-since-burn, and their interaction

\begin{tabular}{lcclllr}
\hline & $d f$ & SS & Mean SS & $F$ & $R^{2}$ & \multicolumn{1}{c}{$p$} \\
\hline Burn severity & 1 & 1.32 & 1.32 & 3.88 & 0.06 & $<0.01$ \\
Time-since-burn & 1 & 1.58 & 1.58 & 4.65 & 0.07 & $<0.01$ \\
Burn severity $\times$ Time- & 1 & 0.66 & 0.66 & 1.96 & 0.03 & 0.03 \\
$\quad$ since-burn & & & & & & \\
Residuals & 55 & 18.73 & 0.34 & & & \\
Total & 58 & 22.29 & & & &
\end{tabular}


Fig. 5 a Corbicular pollen percent nitrogen by burn severity and $\mathbf{b}$ corbicular pollen percent nitrogen regressed across community mean-weighted floral pollen percent nitrogen with $95 \%$ confidence intervals shaded in gray. Mixed-severity samples are blue triangles and high-severity samples are orange circles
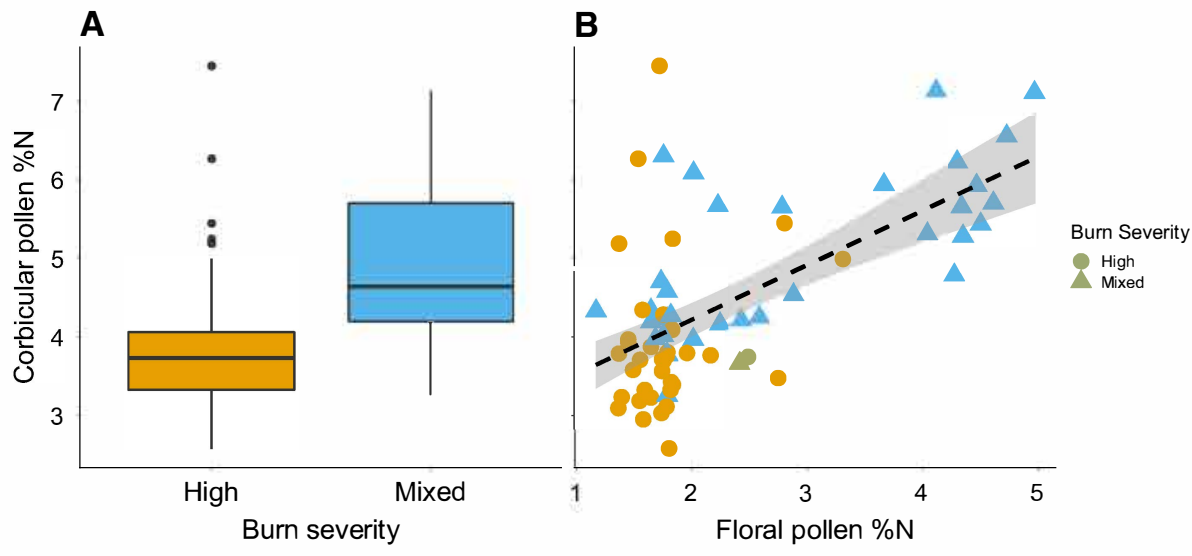

Fig. 6 a Bumble bee percent nitrogen by burn severity and b bumble bee percent nitrogen regressed across time-sinceburn with $95 \%$ confidence intervals shaded in gray. Mixed-severity samples are blue triangles and high-severity samples are orange circles. Points have been horizontally jittered to improve visualization
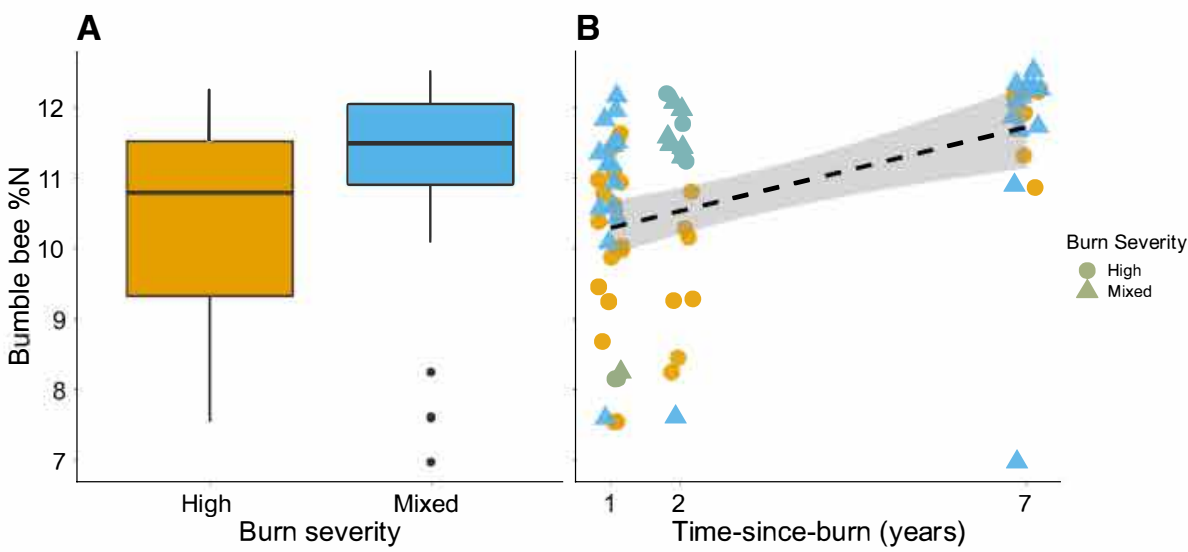

\section{Discussion}

Taken together, our findings suggest that the quality of pollen available to bumble bees and bumble bee nitrogen may be negatively affected by high-severity burns relative to mixed-severity burns. For the floral community, CWM pollen percent nitrogen was significantly lower in high- compared to mixed-severity burns for up to 7 years after wildfire, indicating that burn severity effects on available nutrition are present and persistent for several years following wildfire. This pattern of enhanced floral pollen nitrogen in mixed-severity burns is associated with floral community composition. Similarly, corbicular pollen of bumble bees foraging in high-severity plots had marginally lower percent nitrogen than that of bumble bees collected in mixed-severity plots, and corbicular pollen percent nitrogen was also correlated with the community-level nitrogen content of available floral pollen. Furthermore, bumble bee percent nitrogen was lower in high-severity than in mixed-severity plots, suggesting that bumble bee workers in high-severity burns are being reared on lower quality forage. Bumble bee percent nitrogen increased with greater time-since-burn, indicating that despite the stability in percent nitrogen of available floral pollen across time-since-burn, bumble bees may be able to mitigate the effects of wildfire on their nutritional intake, but only in later plant community successional stages post-wildfire. The reduced nitrogen of available pollen, corbicular pollen, and bumble bees in high-severity burns could be indicators for reduced colony- or landscape-level bee health following homogenizing disturbances like high-severity wildfires.

\section{Quality of floral pollen}

It is well established that plant communities can change dramatically following disturbances like wildfire, and that these changes vary both with the severity of burn as well as successional time post-disturbance (Abella and Fornwalt 2015). Canopy clearing "stand-replacement" fire events generally help to promote vegetation community diversity and abundance (Swanson et al. 2011). Our results demonstrate that wildfire severity can affect the available pollen nitrogen in the regenerating communities, likely via floral community composition differences between 
mixed-and high-severity burns, and that these severity effects o not attenuate with increasing time-since-burn. Although high-severity typically results in abundant floral resources for pollinators (e.g., Galbraith et al. 2019), we did not observe differences in floral abundance between mixed- and high-severity burns. The low percent nitrogen of CWM floral pollen in high-severity plots suggests that, even if abundant, pollen resources after high-severity fire may be nutritionally inadequate. For example, two of the most common species in high-severity, $C$. angustiflium and $S$. betulifolia were species with relatively low pollen percent nitrogen $(1.84 \%$ and $1.07 \%$, respectively, Online Resource 1). By contrast, L. sericeus had the highest pollen percent nitrogen of any species sampled (4.98\%) and was nearly absent from high-severity plots. These results suggest that floral communities of high-severity burns in our study sites were dominated primarily by species with low pollen nitrogen (S. albus, $1.57 \%$, C. angustifolium, $1.84 \%$, and $S$. betulif-lic $1.07 \%$ ), while mixed-severity plots tende to be more dominate by species with higher values of pollen nitrogen (e.g., L. sericeus, $4.98 \% \mathrm{~N}$, Campanula rotundifolia, $2.97 \% \mathrm{~N}$, Phacelia linearis, $4.24 \% \mathrm{~N}$, Arnic cordifolia, $3.63 \% \mathrm{~N}$, Galium boreale, $3.2 \%$, and Cerastium arvense, $4.82 \%$ ).

Furthermore, the lower pollen nitrogen in high-severity burns is still apparent 7 years post-burn, implying that the effects of severe wildfires on available pollen, as well as on species which rely on those resources, may persist at least that long as a legacy of high-severity burns. Additionally, we observed the quality of available pollen to be strongly correlated with the quality of corbicular pollen, providing evidence that bumble bees are collecting lower nitrogen pollen resources in high-severity burns. Bumble bees mix nectar into their corbicular pollen loads when foraging (Goulson 2003), which could slightly reduce the nitrogen content of the pollen load, though we did not test this potential reduction explicitly. Since bumble bees mix relatively similar amounts of nectar into each pollen load, then we expect corbicular pollen nitrogen to still be a reliable measurement of the relative quality of pollen collected by bumble bees in high- vs. mixed-severity burns. Interestingly, corbicular pollen was, on average, of higher percent nitrogen than available floral pollen, and this is likely due to bumble bee foragers being able to selectively forage for high-quality pollen resources (e.g., Vaudo et al. 216) both within and outside of the sampling plot. For example, in mixed-severity plots, even if a low-quality pollen species such as $S$. albus is ominant, the presence of higher quality forage species such as $L$. sericeus would allow for higher quality corbicular pollen collected overall, compared to high-severity burns where those higher quality pollen species are less abundant or absent.

\section{Bumble bee nutrition}

The quality and quantity of pollen resources are important for bee nutrition (Filipiak 2018), bee abundance, and bee species diversity (Potts et al. 2003), yet their relative importance is not well understood. There is strong general support for how organisms can be limited by available nutrition (e.g., Elser et al. 2000). For pollinating insects like bumble bees, the quality of floral resources, particularly pollen, is undeniably important for bumble bee nutrition (Ruedenauer et al. 216). In our study, we observed lower corbicular pollen nitrogen and lower bumble bee nitrogen in high-severity compared to mixed-severity burns, indicating that bumble bees in high-severity burns have lower quality pollen resources available to them, and this may potentially affect their own nutritional state. However, despite both available pollen nitrogen and corbicular pollen nitrogen remaining dissimilar between high- and mixed-severity plots 7 years postburn, bumble bee nitrogen became more similar between burn severities with increasing time-since-burn, indicating that some effects of high-severity burns on bee nutrition may attenuate relatively rapidly with time post-burn.

If bumble bees are nutritionally constrained by the available pollen quality, there could be trade-offs between, e.g., the number and size of workers at the colony-level (Kämper et al. 2016, 2017; Vaudo et al. 2018). For example, if a colony is nutritionally limited by protein from pollen, they may produce fewer or smaller workers (Vanderplanck et al. 2014). Therefore, changes in bumble bee percent nitrogen across time-since-burn could be a result of a quality vs. quantity trade-off with available floral pollen quality that we are unable to fully address with this study as we not have information on colony membership or number of workers. Also, we cannot assume that a bee's corbicular pollen was collected solely from the plot at which the bee was hand-netted. However, given the large spatial extents of the wildfires studied (Table 1) and sampling block sizes ( 15 ha), the corbicular pollen and bee body composition are likely at least a reflection of the burn severity (i.e., high or mixed) within which they were collected. While bumble bees do not appear to compensate for low-quality pollen resources by increasing consumption or larval provisioning, bumble bees have been observed to increase foraging rates based on the quantity of current pollen stores in the colony as well as with higher quality of available floral pollen (Kitaoka and Nieh 2009). Therefore, there may also be trade-offs with regards to quantity and quality of resources at the level of the individual forager.

Bumble bees have been previously found to have relatively consistent body nitrogen levels despite variable quality food intake (Kämper et al. 2017). Our results demonstrate much greater variability in percent nitrogen compare to these previous findings (Kämper et al. 2017). This 
discrepancy between studies may result from our study design including two disturbance treatments with distinctly different floral communities and thus different pollen suites, while Kämper et al. (2017) sampled bumble bees from a single plant community with a narrower suite of available pollen. Furthermore, the mean bumble bee percent nitrogen (ca. 12\%) reported by Kämper et al. (2017) is in a similar range to that of the bees sampled from our oldest burns, while bees from 1 to 2 years post-burn had significantly lower, and much more highly variable, percent nitrogen. Given the lower nitrogen availability in the floral community in our high-severity and early post-burn samples, it seems plausible that bumble bee workers may be nutritionally limited in the early years post-burn within our system.

It is important to note that burned areas, regardless of severity, have undeniable importance to bee species in our study system, with greater abundance and diversity of both bees and floral resources as well as ample nesting resources in burned areas compared to unburned areas (Burkle et al. 2019). Likewise burns have been noted to enhance bee diversity and abundance in other systems when compared to unburned areas (e.g., Mola and Williams 2018; DiCarlo et al. 2019). The unburned floral community sampled for this study contained significantly fewer flowers compared to burned areas (Burkle et al. 2015; Simanonok 2018), likely causing fewer bee observations. Thus, due to a lack of bee samples with corbicular pollen, we were unable to assess the nutritional limitations for bees in unburned areas, or how our results for mixed- or high-severity burns may compare to unburned areas. Future efforts may have to take a different sampling approach in unburned areas to achieve sufficient bee individuals to gain inference for unburned areas. Therefore, while pollen quality may have varied within burn perimeters, as detailed in this study, when comparing burned to unburned areas, it is likely that pollen quantity, or lack thereof, may have more significant effects than pollen quality.

\section{Disturbance and the nutritional landscape}

Anthropogenic influences on floral resources important for bumble bees, both via the diversity of flora as well as the quality of available nutrition (i.e., both pollen and nectar abundance and quality), has been cited as one of the most important issues facing wild bumble bee species (Woodard and Jha 2017). This study is a step towards understanding how the nutritional landscape may be altered by disturbance and how wildfire severity may leave multi-year legacies on the quality of available floral pollen and bumble bee nutrition. In the Anthropocene, ecosystems are not limited to single disturbances like changing fire regimes, as other factors such as habitat loss and climate change act in concert (Potts et al. 2010). In this system, we observed that high-severity burns have lower quality pollen nutrition available for bees. We also observed that bees have lower body percent nitrogen and lower percent nitrogen corbicular pollen in highseverity burns. As high-severity burns continue to increase in frequency and spatial scale (Bowman et al. 2009), there are likely to be more severe impacts on bumble bee communities, due at least in part to nutritional limitations. More detailed nutritional measurements of pollen (e.g., Vaudo et al. 2016, 2018; Filipiak 2018) will provide additional insights into the effects of available nutrition on bumble bees. Future studies may consider studying bee colony density alongside measures of bee nutrition and colony health (e.g., larval mass, number of workers) in the years following wildfire to determine the degree to which bumble bees exhibit trade-offs to adjust to variation in nutrition availability, such as worker longevity, number, or size. Additionally, field-based colony-level measurements of nutrition could help to address the relative importance of quality and quantity of floral resources, particularly post-disturbance.

Acknowledgements Funding for this project was provided by The National Science Foundation (DEB 1256819) and The Graduate School at Montana State University. Field data collection assistance by Dylan Cole, Laura Heil, and Kevin Hogensen. Lab analysis assistance by Jane Klaussen. Our thanks to the reviewers whose suggestions significantly improved this manuscript.

Author contributions statement MPS and LAB conceive and designed the study. MPS performed the study and analyzed the data. MPS and LAB wrote the manuscript.

\section{Compliance with ethical standards}

Conflict of interest The authors declare that they have no conflict of interest.

\section{References}

Abella SR, Fornwalt PJ (2015) Ten years of vegetation assembly after a North American mega fire. Glob Change Biol 21:789 802. https ://doi.org/10.1111/gcb.12722

Bates D, Maechler M, Bolker B, Walker S (2015) Fitting linear mixedeffects models using lme4. J Stat Softw 67(1):1-48. https://doi. org/10.18637/jss.v067.i01

Bowman DMJS, Balch JK, Artaxo P, Bond WJ, Carlson JM, Cochrane MA, D'Antonio CMD, DeFries RS, Doyle JC, Harrison SP, Johnston FH, Keeley JE, Krawchuk MA, Kull CA, Marston JB, Moritz MA, Prentice IC, Roos CI, Scott AC, Swetnam TW, van der Werf GR, Pyne SJ (2009) Fire in the earth system. Science 324:481484. https://doi.org/10.1126/science. 1163886

Burkle LA, Myers JA, Belote RT (2015) Wildfire disturbance and productivity as drivers of plant species diversity across spatial scales. Ecosphere 6(10):202. https://doi.org/10.1890/ES15-00438.1

Burkle LA, Simanonok MP, Durney JS, Myers JA, Belote RT (2019) Wildfires influence abundance, diversity, and intraspecific and interspecific trait variation of native bees and flowering plants across burne and unburned landscapes. Front Ecol Evol 7:252. https://doi.org/10.3389/fevo.2019.00252 
Corby-Harris V, Bowsher JH, Carr-Markell M, Carroll MJ, Centrella M, Cook SC, Couvillon M, DeGrandi-Hoffman G, Dolezal A, Jones JC, Mogren CL (2019) Emerging Themes from the ESA symposium entitled "Pollinator NUTRITION: lessons from bees at individual to landscape levels". Bee World 96(1):1-15. https:// doi.org/10.1080/0005772X.2018.1535951

DiCarlo LAS, DeBano SJ, Burrows S (2019) Short-term response of two beneficial invertebrate groups to wildfire in an arid grassland ecosystem, United States. Rangel Ecol Manag 72(3):551-560. https://doi.org/10.1016/j.rama.2018.11.011

Eidenshink J, Schwind B, Brewer K, Zhu Z-L Quayle, Howard BS (2007) A project for monitoring trends in burn severity. Fire Ecol Sp Issue 3(1):3-21. https://doi.org/10.4996/fireecology.0301003

Elser JJ, Fagan WF, Denno RF, Dobberfuhl DR, Folarin A, Huberty A, Interlandi S, Kilham SS, McCauley E, Schulzz KL, Siemann EH, Sterner RW (2000) Nutritional constraints in terrestrial and freshwater food webs. Nature 408(30):578-580. https://doi. org/10.1038/35046058

Filipiak M (2018) A better understanding of bee nutritional ecology is neede to optimize conservation strategies for wild beesthe application of ecological stoichiometry. Insects. https://doi. org/10.3390/insects 9030085

Galbraith SM, Cane JH, Moldenke AR, Rivers JW (2019) Wild bee diversity increases with local fire severity in a fire-prone landscape. Ecosphere 10(4):e02668. https://doi.org/10.1002/ecs2.2668

Goulson D (2003) Bumblebees: their behaviour and ecology, 1st edn. -xford University Press, USA

Hanley ME, Franco M, Pichon S, Darvill B, Goulson D (2008) Breeding system, pollinator choice and variation in pollen quality in British herbaceous plants. FunctEcol 22(4):592 598. https://doi. org/10.1111/j j.1365-2435.2008.01415.x

Hessburg PF, Smith BG, Salter RB (1999) Detecting change in forest spatial patterns from reference conditions. Ecol Appl 9:1232 1252. https://doi.org/10.1890/1051-0761(1999)009\%5b 123 2:DCIFSP\% 5 d2.0.C ;2

Hessburg PF, Agee JK, Franklin JF (2005) Dry forests and wildland fires of the inland Northwest USA: contrasting the landscape ecology of the pre-settlement and modern eras. For Ecol Manag 211:117 139. https://doi.org/10.1016/j.foreco.2005.02.01

Hutto RL, Belote RT (2013) Distinguishing four types of monitoring based on the questions they address. For Ecol Manag 289:183 189. https://doi.org/10.1016/j.foreco.2012.10.005

Kämper W, Werner PK, Hilpert A, Westphal C, Bliithgen N, Eltz T, Leonhardt SD (2016) How landscape, pollen intake and pollen quality affect colony growth in Bombus terrestris. Landsc Ecol 31(10):2245-2258. https://doi.org/10.1007/s10980-016-0395-5

Kämper W, Weiner C, Kiihsel S, Storm C, Thomas ELTZ, Bliithgen $\mathrm{N}$ (2017) Evaluating the effects of floral resource specialisation and of nitrogen regulation on the vulnerability of social bees in agricultural landscapes. Apidologie 48(3):371 383. https://doi. org/10.1007/s 13592-016-0480-4

Kincaid TM, lsen AR (2011) spsurvey: spatial survey design and analysis. $\mathrm{R}$ package version 3.4

Kitaoka TK, Nieh JC (2009) Bumble bee pollen foraging regulation: role of pollen quality, storage levels, and odor. Behav Ecol Sociobiol 63:501 510. https://doi.org/10.1007/s00265-008-0684-3

Kriesell L, Hilpert A, Leonhardt SD (2017) Different but the same: bumblebee species collect pollen of different plant sources but similar amino acid profiles. Apidologie 48(1):102 116. https:// doi.org/10.1007/s13592-016-0454-6

Kuznetsova A, Brockhoff PB, Christensen RHB (2017) lmerTest package: tests in linear mixed effects models. J Stat Softw 82(13):1 26. https://doi.org/10.18637/jss.v082.i13

Mapalad KS, Leu D, Nieh JC (2008) Bumble bees heat up for high quality pollen. J Exp Biol 211:2239 2242. https://doi. org/10.1242/jeb.016642
Milchunas DG, Lauenroth WK (1993) Quantitative effects of grazing on vegetation and soils over a global range of environments. Ecol Monogr 63(4):327-366. https://doi.org/10.2307/2937150

Mola JM, Williams NM (2018) Fire-induced change in floral abundance, density, and phenology benefits bumble bee foragers. Ecosphere 9(1):e02056. https://doi.org/10.1002/ecs2.2056

Oksanen J, Blanchet G, Friendly M, Kindt R, Legendre P, McGlinn D, Minchin R, 'Hara B, Simpson GL, Solymos P, Stevens MHH, Szoecs E, Wagner H (2018) vegan: community ecology package. $\mathrm{R}$ package version 2.5-3.

Osborne JL, Clark SJ, Morris RJ, Williams IH, Riley JR, Smith AD, Reynolds DR, Edwards AS (2001) A landscape-scale study of bumble bee foraging range and constancy, using harmonic radar. J Appl Ecol 36:519-533. https://doi.org/10.104 6/j. 1365-2664.1999.00428.x

Potts SG, Vulliamy B, Dafni A, Ne'eman G, 'Toole •, Roberts C, Wilmer SP (2003) Response of plant-pollinator communities to fire: changes in diversity, abundance and floral reward structure. Oikos 101:103-112. https://doi.org/10.103 4/j.1600-0706.2003.12186.x

Potts SG, Biesmeijer JC, Kremen C, Neumann P, Schweiger Kunin WE (2010) Global pollinator declines: trends, impacts and drivers. Trends Ecol Evol 25(6):345-353. https://doi. org/10.1016/j.tree.2010.01.007

R Core Team (2018) R: A language and environment for statistical computing. R Foundation for Statistical Computing, Vienna

Roberts DW (2016) labdsv: ordination and multivariate analysis for ecology. R package version 1.8-0.

Rotheray EL, Osborne JL, Goulson D (2017) Quantifying the food requirements and effects of food stress on bumble bee colony development. J Apic Res 56(3):288 299. https://doi. org/10.1080/00218839.2017.1307712

Roulston TH, Cane JH, Buchmann SL (2000) What governs protein content of pollen: pollinator preferences, pollen-pistil interactions, or phylogeny? Ecolog Monogr 70(4):617 643. https ://doi.org/10.1890/0012-9615(2000)070\%5b0617:WGPC P\% 5 2.0.C ;2

RuedenauerFA, Spaethe J, Leonhardt SD (2015) How to know which food is good for you: bumblebees use taste to discriminate between different concentrations of food differing in nutrient content. J Exp Biol 218:2233 2240. https://doi.org/10.1242/ jeb. 118554

Ruedenauer FA, Spaethe J, Leonhardt SD (2016) Hungry for quality individual bumblebees forage flexibly to collect highquality pollen. Behav Ecol Sociobiol 70:1209-1217. https:// doi.org/10.1007/s00265-016-2129-8

Saifuddin M, Jha S (2014) Colony-level variation in pollen collection and foraging preferences among wild-caught bumble bees (Hymenoptera: Apidae). Environ Entomol 43(2):393-401. https ://doi.org/10.1603/EN13261

Simanonok MP (2018) Plant-pollinator network assembly after wildfire. PhD dissertation, Department of Ecology, Montana State University, Bozeman, Montana, USA

Swanson ME, Franklin JF, Beschta RL, Crisafulli CM, DellaSala DA, Hutto RL, Lindenmayer DB, Swanson FJ (2011) The forgotten stage of forest succession: early-successional ecosystems of forest sites. Front Ecol Environ 9(2):1 17-125. https://doi. org/10.1890/090157

Tasei JN, Aupinel P (2008) Nutritive value of 15 single pollens and pollen mixes tested on larvae produced by bumblebee workers (Bombus terrestris, Hymenoptera: Apidae). Apidologie 39:397409. https://doi.org/10.1051/apido:2008017

Travers SE (1999) Pollen performance of plants in recently burned and unburned environments. Ecology 80(7):2427 2434. https ://doi.org/10.1890/0012-9658(1999)080\%5b2427:PPOPI $\mathrm{R} \% 5 \mathrm{~d} 2.0 . \mathrm{C} ; 2$ 
Vanderplanck M, Moerman R, Rasmont P, Lognay G, Wathelet B, Wattiez R, Michez D (2014) How does pollen chemistry impact development and feeding behavior of polylectic bees? PLoS One 9(1):e86209. https://doi.org/10.1371/journal.pone.0086209

Vaudo AD, Patch HM, Mortensen DA, Tooker JF, Grozinger CM (2016) Macronutrient ratios in pollen shape bumble bee (Bombus impatiens) foraging strategies and floral preferences. Proc Natl Acad Sci 113(28):E4035 E4042. https://doi. org/10.1073/ pnas. 1606101113

Vaudo AD, Farrell LM, Patch HM, Grozinger CM, Tooker JF (2018) Consistent pollen nutritional intake drives bumble bee (Bombus impatiens) colony growth and reproduction across different habitats. Ecol Evol 8(11):5765-5776. https://doi.org/10.1002/ ece 3.4115

Wan S, Huig D, Luo Y (2001) Fire effects on nitrogen pools and dynamics in terrestrial ecosystems: a meta-analysis. Ecol Appl 11(5):1349 1365. https://doi.org/10.1890/10510761(2001)011\%5b1349:FE@NA\%5 2.0.CO;2

Woodard SH, Jha S (2017) Wild bee nutritional ecology: predicting pollinator population dynamics, movement, and services from floral resources. Curr Opin Insect Sci $21: 83$ 90. https://doi. org/10.1016/j.cois.2017.05.011 